\title{
Ayurvedic metal nanoparticles could be novel antiviral agents against SARS-CoV-2
}

\author{
Prasanta Kumar Sarkar ${ }^{1}$. Chitrangada Das Mukhopadhyay ${ }^{2}$
}

Received: 14 October 2020 / Accepted: 21 December 2020 / Published online: 6 January 2021

(c) Islamic Azad University 2021

\begin{abstract}
Purpose of review The pandemic COVID-19 has affected more than seventy million people globally. The whole world is eagerly waiting for an effective antiviral therapy to combat COVID-19, but it is yet to get. The emergence of COVID-19 makes imperative the need for safe and potent antiviral drugs. Many metal nanoparticles exhibit significant antiviral potential against many viral diseases. The Ayurvedic system of medicine is the treasure of many metal nanoparticulate drugs termed as Bhasma.

Recent findings Gold, silver, copper, zinc and iron oxide nanoparticles are effective against coronavirus. A possible mechanism of action of the metal nanoparticles against coronavirus is a disruption of outer layers of coronavirus. Swarna Bhasma, Rajata Bhasma, Tamra Bhasma and Yashada Bhasma are recommended for COVID-19 treatment due to the ability to reduce the plasma interleukins, interferons and TNF $\alpha$ levels.

Summary The Ayurvedic Bhasma preparations are unique metal nanoparticles. These metal nanoparticles are safe, stable in solid state and are having excellent biological activities. Ayurvedic metal nanoparticles, Swarna Bhasma, Rajata Bhasma, Tamra Bhasma and Yashada Bhasma could be proved as novel antiviral agents against SARS-CoV-2 for their anti-inflammatory, immunomodulatory, antiviral and adjuvant activities.
\end{abstract}

Keywords Ayurveda $\cdot$ Bhasma $\cdot$ COVID-19 $\cdot$ Metal $\cdot$ Nanoparticles $\cdot$ SARS-CoV-2

\section{Introduction}

The cases of COVID-19 are increasing worldwide in a ladder pattern manner. And still, there is no evidence-based treatment for COVID-19 in any system of medicine; through different kind of pharmacological and clinical interventions are being employed all over the world. The search for an effective treatment against COVID-19 is still wide open, though many different antiviral agents are tested or under testing in clinical trials to assess their efficacy against the SARS-CoV-2 [1]. In this context, Ayurveda, the traditional Indian system of medicine may play an important role. This

Prasanta Kumar Sarkar

prasantaksarkar@yahoo.com

1 Department of Rasashastra, J. B. Roy State Ayurvedic Medical College and Hospital West Bengal University of Health Sciences, Kolkata 700004, West Bengal, India

2 Centre for Healthcare Science and Technology, Indian Institute of Engineering Science Technology, Shibpur, Howrah 711103, West Bengal, India system has the potential to combat COVID-19. The needs are conducting research activities, proper monitoring and data-keeping during implementation [2].

In recent times, virus infections are posing significant global health challenges. Several epidemics occurred in the past few years due to virus; MARS, SARS, swine flu are few of those. So many antiviral therapies and vaccines are available, yet it is considered that development of a safe, effective and potent antiviral therapy is the need of time. The reasons are being the occurrence of resistant virus strains, the adverse effect of the present therapies and weak response of the vaccines [3]. There is a need for an effective antiviral medicine urgently. Nanotechnology may play a vital role in the prevention and treatment of COVID-19. The metal nanoparticles have enormous potential to combat COVID-19 [1].

The emergence of the COVID-19 as a pandemic again makes imperative the need for such safe and potent antiviral drugs. The metal nanoparticles exhibit significant antiviral potential against many viral diseases. Metal nanoparticles can block cell attachment and viral entry into the cells, can inhibit viral proliferation and replication, can cause viral 
inactivation and are having viricidal effects [4]. Many metal nanoparticles are used as therapeutic entities in Ayurveda for hundreds of years. In this context, the Ayurvedic Bhasma preparations, which are biologically produced metals and mineral nanoparticles have the potential to emerge as novel antiviral agents against SARS-CoV-2 by their unique chemical and physical properties. The probable role of the Bhasma preparation for combating COVID-19 is searched and discussed in this review article.

\section{Antiviral effects of metal nanoparticles}

Metal nanoparticles are studied for the past few years for antiviral activities. And many metal nanoparticles are found to have significant effects on many viruses. These nanoparticles exhibited a huge opportunity for the management of various viral diseases. There is another possibility too; a chance for the development of resistance to the metal nanoparticles will be minimum as these nanoparticles can attack a broad range of targets in the virus [5]. The metal nanoparticles are very effective antioxidants; these can influence the production of ROS species by acting as ion reservoirs for the controlled release of bioactive ions. They are capable to go through the cell membrane due to very small size $(<10 \mathrm{~nm})$ and can inhibit post-attachment virus replication [6].

Gold nanoparticles can bind with the envelop glycoprotein of HIV and inhibit virus replication, it also shows antiviral effects against subtypes of influenza virus (e.g., H1N1, H3N2, H5N1) [7]. Gold nanoparticles were evaluated as a vaccine platform against the West Nile virus to access the immune response. The gold nanoparticles were coated with West Nile virus envelop protein. The antivirus antibody was measured after inoculation in mice [8].

The silver nanoparticles were reported to have significant antiviral activities against a wide range of virus-like human immunodeficiency virus, hepatitis B virus, herpes simplex virus, monkeypox virus and respiratory syncytial virus. The silver nanoparticles exhibit a virucidal effect by inhibiting virus reproduction. It can interact with cell receptors and prevent virus entry into the host cell in case of HIV-1 virus. It can also inhibit double strain RNA virus replication by interacting with the virus genome [9]. The silver nanoparticles at a concentration of $3.125-12.5 \mu \mathrm{g} / \mathrm{ml}$ reduced the virus titre and the number of apoptotic cells elicited by transmissible gastroenteritis virus (TGEV) [10].

Copper compounds nanoparticles in oxide, iodide and sulphide forms exhibited significant antiviral activities against herpes simplex virus, H1N1 influenza virus and human norovirus, respectively. The copper oxide nanoparticles can reduce the viral population. Copper iodide nanoparticles inactivate activity of H1N1 influenza virus. Copper sulphide nanoparticles show a virucidal effect against human norovirus by degrading the capsid protein [11]. The silver-copper alloy nanoparticles can also inhibit HIV replication by binding with envelop glycoprotein gp120 [12].

Metal oxide nanoparticles such as iron oxide, zinc oxide have demonstrated specific antiviral activities. Iron oxide nanoparticles exhibit antiviral efficacy against human immunodeficiency virus [13]. Ferromagnetic $\left(\mathrm{Fe}_{3} \mathrm{O}_{4}\right)$ nanoparticles can inactivate twelve different subtypes $(\mathrm{H} 1-\mathrm{H} 12)$ of influenza A viruses by targeting the viral envelopes [14].

\section{Metals effective against SARS-CoV}

Metals form components of several viral proteins and play an important role in the survival and pathogenesis of the viruses. For nucleocapsid protein-transactivation response (TAR)-RNA interactions in viruses, metals ions are needed. Magnesium, zinc and copper are the commonest metal ions that bind with the viral proteins [15].

A recent study reported that a gold drug, Auronafin reduced the expression of SARS-COV-2-induced cytokines in human cells. It is an FDA approved drug that contains gold with triethyl phosphine used for the treatment of rheumatoid arthritis. The study claimed that it could be a useful drug to limit SARS-CoV-2 infection and associated lung injury [16].

A study reported that zinc combined with pyrithione can inhibit the replication of SARS-CoV by impairment of replication of the RNA viruses in cell culture. Zinc exhibited activity against RNA polymerase of multiprotein replication and transcription complexes of SARS-CoV and can significantly inhibit the replication [17].

A hypothesis is made that a combination of chloroquine or hydroxychloroquine with zinc, and an antibiotic like azithromycin will be an effective remedy against COVID-19. The reasons behind this combination are the broad availability, affordability, and demonstrated the efficacy and safety of this combination [18].

\section{Metal nanoparticles affect SARS-CoV-2 targets}

The possible targets are very important for the development of a novel drug to combat SARS-CoV-2. Different studies have identified various structural targets of SARS-CoV-2. Most of the studies targeted spike (S) protein; the other targets include RNA-dependent RNA polymerase, main protease/M Pro/3CL pro and nonstructural protein 15 Endoribonuclease [19]. The target protein structures of SARS$\mathrm{CoV}-2$ are essential for drug designing against the virus. The metal and mineral nanoparticles can exhibit activity against 
many of these structural targets and can inhibit replication of SARS-CoV-2 [20].

The gold and silver nanoparticles are significant virucidal agents to neutralize the infectious viral particles. The effects are due to upregulating the production of endogenous protective factors and suppressing the cytokine storm [21]. The gold nanoparticles exhibited activity against $\mathrm{S}$ protein. Zinc ionophores are effective as antiviral agents. Zinc nanoparticles can target the RNA-dependent RNA polymerase. Zinc nanoparticles inhibit RNA synthesis by increasing intracellular $\mathrm{Zn} 2+$ concentrations [22].

Molecular docking of iron oxide $\left(\mathrm{Fe}_{2} \mathrm{O}_{3}\right.$ and $\left.\mathrm{Fe}_{3} \mathrm{O}_{4}\right)$ nanoparticles with spike protein receptor-binding domain (S-RBD) of SARS-CoV-2 was investigated. The study reported that both the iron oxide nanoparticles interacted with S-RBD. It was also revealed that a more stable compound was formed by $\mathrm{Fe}_{3} \mathrm{O}_{4}$ with S-RBD [23].

Copper (II) was evaluated for making a bond with coronavirus main protease (Mpro). Copper (II) can make a bond to the CYS 145 thiolate in the Mpro active-site region. Copper (II) can inhibit the enzyme function by a break up the internal $\mathrm{H}$-bond network by binding to the imidazole side chain of this histidine [24].

A possible mechanism of action of the metal nanoparticles against coronavirus is a disruption of the outer layers of the coronavirus. This mechanism is inferred, because the metal nanomaterials are effective against the representative of coronavirus but at the same time, they do not show effect against an envelope-free infectious bursal disease virus [21].

\section{Metal nanoparticles as COVID-19 vaccine adjuvants}

Metal nanoparticles are being used as vaccine adjuvants with the vaccine against many viral diseases. The antibodies titre in organisms immunized with metal nanoparticlesupplemented vaccines is increased many folds. Vaccines are yet to available against novel SARS coronavirus, but works are on progress using the metal nanoparticles to achieve the immunostimulatory effect against coronaviruses [21].

It was reported that gold nanoparticles are having significant vaccine adjuvant properties and the coated gold nanoparticles act by increasing inflammatory cytokines (TNF- $\alpha$, IL-6, IL-12) production [25]. Gold nanoparticle complexes with transmissible gastroenteritis virus (TGEV) exhibited higher levels of IFN- $\gamma$, IL- $1 \beta$ and IL- 6 in animals immunized with the complexes than those in animals challenged with only antigen [26]. The same complexes of gold nanoparticles with TGEV antigen enhanced respiratory activity of peritoneal macrophages and higher plasma IFN- $\gamma$ levels in comparison to the attenuated virus alone [27]. Vaccination with S protein antigen and gold nanoparticles in an avian model of coronavirus infection increased the splenic T-cell response, produced stronger antibody titres and enhanced the lymphatic antigen delivery in comparison to vaccination with inactivated virus vaccine [28].

Gold nanoparticles were studied as vaccine adjuvant against SARS coronavirus. S-protein of coronavirus was targeted for blocking coronavirus infection. The gold nanoparticles were used as the carrier of the antigen and as an adjuvant with the subunit vaccines. It was observed that the antigen adjuvanted by gold nanoparticles exhibited strong antigen-specific $\mathrm{IgG}$ response against SARS-CoV infection in BALB/c mice [29].

\section{Ayurvedic metallic nanomedicines}

The Ayurvedic system of medicine is the treasure of metallic and mineral nanomedicines. A branch of Ayurveda, Rasashastra deals with preparation and therapeutic applications of nanomedicines, especially metallic and mineral nanoparticles. These metals and minerals are processed with various organic materials and repeated heating, and the finally prepared metal or mineral ashes are claimed to be organically structured nanoparticles. This prepared organometallic or organo-mineral nanoparticles are termed as Bhasma in Ayurveda [30]. These preparations are reported to be safe for human use and are having various biological activities [31].

Swarna Bhasma (incinerated gold) analysed by X-ray diffraction (XRD) and transmission electron microscope (TEM) reveals that the size of crystallites within the Swarna Bhasma is approximately 30-60 nm [32]. Rajata Bhasma (incinerated silver) by scanning electron microscopy (SEM) analysis shows the regular and uniform arrangement of a cluster of granules in Rajata Bhasma. The sizes of the particles range from 10 to $60 \mathrm{~nm}$ [33]. The X-ray diffraction (XRD) analysis of Tamra Bhasma (incinerated copper) reveals that it is nanocrystalline and has a size of less than $100 \mathrm{~nm}$ [34]. Lauha Bhasma (incinerated iron) shows irregular aggregates of various sizes and shapes with nanostructure on the surfaces (100—500 nm) [35]. Naga Bhasma (incinerated lead) contains nanoscale structures on the surface. The width of the nanostructures lies between 30 and $50 \mathrm{~nm}$, while the length ranges between 100 and $160 \mathrm{~nm}$ [36]. The SEM images suggest that the Vanga Bhasma (incinerated tin) particles show granular appearance and porous morphology. These nanoparticles have spherical morphology with the size smaller than $100 \mathrm{~nm}$ [37]. Particle size analysis by XRD shows that the mean particle size of Yashada Bhasma (incinerated zinc) is $49-80 \mathrm{~nm}$. The particles are smooth, 
spherical and present in aggregates as suggested by SEM analysis [38].

\section{Ayurvedic Bhasma for COVID-19 treatment}

Several Ayurvedic Bhasma preparations are mentioned to be useful for COVID-19 treatment. These preparations are effective through sublingual and oral route due to better bioavailability and absorption on account of the presence of nanoparticles. Shiddha Makaradwaja (nano$\mathrm{HgS}$ particles) and Swarna Bhasma (nanogold particles) are mentioned to be effective through administration with black pepper powder and ghee for treatment of moderate to severe COVID-19 patients [2]. Many Ayurvedic formulations are proposed for preventive and curative purposes to combat COVID-19. These preparations contain Swarna Bhasma (gold nanoparticles), Rajata Bhasma (silver nanoparticles), Tamra Bhasma (copper nanoparticles), Lauha Bhasma (iron nanoparticles) and Vanga Bhasma (tin nanoparticles) [39].

\section{Immunomodulatory therapy}

Drugs having immunomodulation effect are proposed for COVID-19 therapy. Many Ayurvedic Bhasma preparations are having immunomodulation effect. Swarna Bhasma exhibits immunostimulant activity on macrophage functions and promotes phagocytic activity [40]. The experimental evidence indicates that Swarna Bhasma can be used to improve the immune responses [41]. Yashada Bhasma exhibits T-cell mediate immune response modulation [38]. The immunomodulatory drugs may downregulate the adhesion molecules of the cell surface and reduce pro-inflammatory cytokines production. These drugs may stimulate phagocytosis caused by alveolar macrophages and inhibit neutrophil activation and mobilization.

\section{Inflammation inhibitors}

Anti-inflammatory drugs are helpful for the treatment of COVID-19, because cytokine storms causing injury and exacerbation are common in COVID-19 cases. Therefore, the drug agents which inhibit inflammation are effective against COVID-19. Many Bhasma preparations have inflammation inhibition activity. Swarna Bhasma, Rajata Bhasma, Tamra Bhasma, Yashada Bhasma have inflammation inhibition activity. Swarna Bhasma is an anti-inflammatory drug that reduces cytokines production and stimulates both cellular and humoral immune response. It can influence $\mathrm{T}-$-cell activity thus increases vascular permeability and encourage vasodilatation [41]. Tamra Bhasma is reported to have significant inflammation inhibition activity. This is achieved by reduced production of interleukins and TNF- $\alpha$ [42].

\section{Antiviral effects}

Some metal nanoparticles exhibit a virucidal effect by destroying the envelope of the viruses or by inhibiting virus reproduction. Swarna Bhasma may affect the spike protein and can disrupt outer layers of the coronavirus. Rajata Bhasma can inhibit reproduction of novel coronavirus. Tamra Bhasma may exhibit a virucidal effect against SARSCoV-2 by degrading the capsid protein $[43,44]$.

\section{Vaccine adjuvant}

The Ayurvedic Bhasma preparations having Rasayana (immunomodulator) effect may be used as vaccine adjuvant. Ayurvedic immunomodulators can be administered along with the COVID-19 vaccines to elicit a faster and stronger immune response. Swarna Bhasma containing gold nanoparticles may act as an effective vaccine adjuvant for the stronger immune response with the COVID-19 vaccines by increasing levels of IFN- $\gamma$, IL- $1 \beta$ and IL- 6 . The other Bhasma preparations with an immunomodulatory effect like Yashada Bhasma may also be effective as vaccine adjuvant to increase immune response.

Table 1 Action mechanism of Ayurvedic metal nanoparticles on SARS-CoV-2

\begin{tabular}{llll}
\hline Ayurvedic preparations & Metal nanoparticles & Possible targets & Reference \\
\hline Swarna Bhasma & Gold nanoparticles & Binding with S protein & Sekimukhi et al. 2020 \\
& & Bind with the envelop glycoprotein & Di Gianvincenzo et al. 2010 \\
Rajata Bhasma & Silver nanoparticles & Interacting with virus genome & Kerry et al. 2019 \\
Tamra Bhasma & Copper nanoparticles & CYS 145 thiolate in the coronavirus main & Garza-López et al. 2020 \\
& & protease active-site & Abo-zeid et. al. 2020 \\
Lauha Bhasma & Iron nanoparticles & S protein receptor-binding domain & Barnard et al. 2011 \\
Yashada Bhasma & Zinc nanoparticles & RNA-dependent RNA polymerase &
\end{tabular}




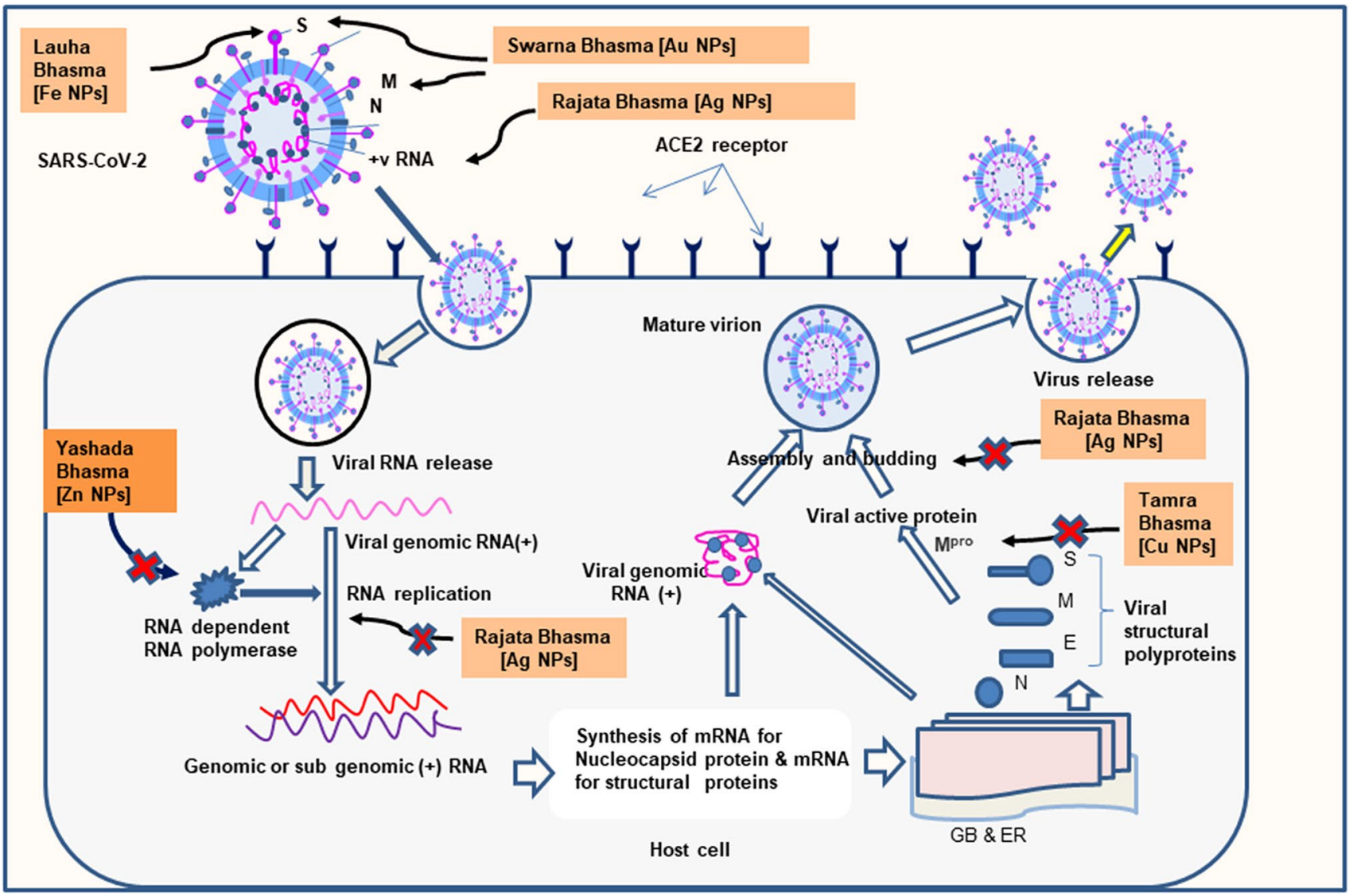

Fig. 1 Mechanism of action of Various Ayurvedic metal nanoparticles against SARS-CoV 2: $N$ Nanoparticles, $S$ Spike glycoprotein, $M$ Membrane glycoprotein, $N$ Nucleocapsid phosphoprotein, Mpro Main protease, GB Golgi bodies, ER Endoplasmic reticulum

A hypothesis has been drawn that silver, copper, and zinc nanoparticles will be effective to fight against COVID-19 due to their antimicrobial properties to prevent contamination and contagion. Emphasis has been given to use of copper salt nanoparticles for having antiviral effects [1]. By considering this hypothesis, it may be inferred that Rajata Bhasma (silver nanoparticles), Yashada Bhasma (zinc nanoparticles), Tamra Bhasma (copper nanoparticles) and Bhasma of copper-containing drugs like Makshika Bhasma (chalcopyrite nanoparticles) will be effective for combating COVID-19 (Table 1). The probable mechanism of action of Ayurvedic metal nanoparticles against SARS-CoV-2 is presented in Fig. 1.

The World Health Organization has reported that plasma cytokines level, interferons alpha (IFN $\alpha)$, interferons gamma (IFN $\gamma$ ) and tumour necrosis factor-alpha (TNF $\alpha$ ) increase in patients due to the COVID-19 infection [45]. The Ayurvedic metal nanoparticles i.e. Swarna Bhasma, Rajata Bhasma, Tamra Bhasma, Yashada Bhasma have the ability to reduce the plasma interleukins, interferons and $\mathrm{TNF} \alpha$ levels. The efficacy of these nanomedicines can be evaluated by determining these plasma biomarkers before and after treatment.

\section{Conclusion}

Research works on uses of metal nanoparticles for combating COVID-19 are merely sporadic, although the metal nanoparticles have enormous potential to affect the possible therapeutic targets of SARS-CoV-2. Ayurvedic metal nanoparticles, especially Swarna Bhasma, Rajata Bhasma, Tamra Bhasma and Yashada Bhasma could be proved as novel antiviral agents against SARS-CoV-2 due to their anti-inflammatory, immunomodulatory, antiviral and adjuvant activities.

Acknowledgements The authors acknowledge contribution of Dr. B. Ravishankar for preparation of this manuscript.

Author contributions Both the authors have contributed equally; they have accumulated, analysed and interpreted the data and information.

Funding Not applicable. 


\section{Compliance with ethical standards}

Conflict of interest The authors declare that they have no conflict of interest.

\section{References}

1. Sportelli, M.C., Izzi, M., Kukushkina, E.A., Hossain, S.I., Picca, R.A., Ditaranto, N., Cioffi, N.: Can Nanotechnology and Materials Science Help the Fight against SARS-CoV-2? Nanomaterials 10, 802 (2020). https://doi.org/10.3390/nano10040802

2. Rastogi, S., Pandey, D.N., Singh, R.H.: COVID-19 pandemic: a pragmatic plan for Ayurveda intervention. J. Ayurveda Integr. Med. (2020). https://doi.org/10.1016/j.jaim.2020.04.002

3. Galdiero, S., Falanga, A., Vitiello, M., Cantisani, M., Marra, V., Galdiero, M.: Silver nanoparticles as potential antiviral agents. Molecules 16, 8894-8918 (2011). https://doi.org/10.3390/molec ules 16108894

4. Medhi, R., Srinoi, P., Ngo, N., Tran, H.V., Lee, T.R.: Nanoparticle-Based Strategies to Combat COVID-19. ACS Appl. Nano Mater. 3, 8557-8580 (2020)

5. Aderibigbe, B.A.: Metal-based nanoparticles for the treatment of infectious diseases. Molecules 22, 1370 (2017). https://doi. org/10.3390/molecules22081370

6. Rai, M., Deshmukh, S.D., Ingle, A.P., Gupta, I.R., Galdiero, M., Galdiero, S.: Metal nanoparticles: the protective nano shield against virus infection. Crit. Rev. Microbiol. 42, 46-56 (2016)

7. Di Gianvincenzo, P., Marradi, M., Martínez-Ávila, O.M., Bedoya, L.M., Alcamí, J., Penadés, S.: Gold nanoparticles capped with sulfate-ended ligands as anti-HIV agents. Bioorganic Med. Chem. Lett. 20, 2718-2721 (2010)

8. Niikura, K., Matsunaga, T., Suzuki, T., Kobayashi, S., Yamaguchi, H., Orba, Y., Kawaguchi, A., Hasegawa, H., Kajino, K., Ninomiya, T., Ijiro, K., Sawa, H.: Gold nanoparticles as a vaccine platform: influence of size and shape on immunological responses in vitro and in vivo. ACS Nano 7(5), 3926-3938 (2013). https:// doi.org/10.1021/nn3057005

9. Kerry, R.G., Malik, S., Redda, Y.T., Sahoo, S., Patra, J.K., Majhi, S.: Nano-based approach to combat emerging viral (NIPAH virus) infection. Nanomed. Nanotechnol. Biol. Med. 18, 196-220 (2019)

10. Lv, X., Wang, P., Bai, R., Cong, Y., Suo, S., Ren, X., Chen, C.: Inhibitory effect of silver nanomaterials on transmissible virusinduced host cell infections. Biomaterials 35(13), 4195-4203 (2014)

11. Ishida, T.: Antiviral activities of $\mathrm{Cu} 2+$ ions in viral prevention replication, RNA degradation, and for antiviral efficacies of lytic virus, ROS-mediated virus, copper chelation. World Sci. News 99, 148-168 (2018)

12. Elechiguerra, J.L., Burt, J.L., Morones, J.R., Camacho-Bragado, A., Gao, X., Lara, H.H., Yacaman, M.J.: Interaction of silver nanoparticles with HIV-1. J. Nanobiotechnol. 3, 6 (2005)

13. Singh, L., Kruger, H.G., Maguire, G.E.M., Govender, T., Parboosing, R.: The role of nanotechnology in the treatment of viral infections. Ther. Adv. Infectious Dis. 4(4), 105-131 (2017). https ://doi.org/10.1177/2049936117713593

14. Qin, T., Ma, R., Yin, Y., Miao, X., Chen, S., Fan, K., Xi, J., Liu, Q., Gu, Y., Yin, Y., Hu, J., Liu, X., Peng, D., Gao, L.: Catalytic inactivation of influenza virus by iron oxide nanozyme. Theranostics 9, 6920-6935 (2019)

15. Chaturvedi, U.C., Shrivastava, R.: Interaction of viral proteins with metal ions: role in maintaining the structure and functions of viruses. FEMS Immunol. Med. Microbiol. 43, 105-114 (2005)
16. Rothan, H.A., Stone, S., Natekar, J., Kumari, P., Arora, K., Kumar, M.: The FDA-approved gold drug Auranofin inhibits novel coronavirus (SARS-COV-2) replication and attenuates inflammation in human cells. Biorxiv.org (2020). https://doi. org/10.1101/2020.04.14.041228

17. Tevelthuis, A.J.W., van den Worm, S.H.E., Sims, A.C., Baric, R.S., Snijder, E.J., van Hemert, M.J.: Zn2+ inhibits Coronavirus and Arterivirus RNA Polymerase activity invitro and zinc ionophores block the replication of these viruses in cell culture. PLoS Pathog. 6(11), e1001176 (2010)

18. Derwand, R., Scholz, M.: Does zinc supplementation enhance the clinical efficacy of chloroquine/hydroxychloroquine to win today's battle against COVID-19? Med. Hypotheses 142, 109815 (2020). https://doi.org/10.1016/j.mehy.2020.109815

19. Prajapat, M., Sarma, P., Shekhar, N., Prakash, A., Avti, P., Bhattacharyya, A., Kaur, H., Kumar, S., Bansal, S., Sharma, A.R., Medhi, B.: Update on the target structures of SARSnCoV-2: a systematic review. Indian J. Pharmacol. 52, 142-149 (2020)

20. Wu, C., Liu, Y., Yang, Y., Zhang, P., Zhong, W., Wang, Y., Wang, Q., Xu, Y., Li, M., Li, X., Zheng, M., Chen, L., Li, H.: Analysis of therapeutic targets for SARS-CoV-2 and discovery of potential drugs by computational methods. Acta. Pharm. Sin. B 10(5), 766-788 (2020). https://doi.org/10.1016/j. apsb.2020.02.008

21. Uskoković, V.: Why have nanotechnologies been underutilized in the global uprising against the coronavirus pandemic? Nanomedicine (2020). https://doi.org/10.2217/nnm-2020-0163

22. Barnard, D.L., Kumaki, Y.: Recent developments in anti-severe acute respiratory syndrome coronavirus chemotherapy. Future Virol. 6(5), 615-631 (2011). https://doi.org/10.2217/fvl.11.33

23. Abo-zeid, Y., Ismail, N.S.M., McLean, G.R., Hamdy, N.M.: A molecular docking study repurposes FDA approved iron oxide nanoparticles to treat and control COVID-19 infection. Eur. J. Pharm. Sci. 153, 105465 (2020)

24. Garza-López, R.A., Kozak, J.J., Gray, H.B.: Copper(II) Inhibition of the SARS-CoV-2 Main Protease. ChemRxiv. (2020). https:// doi.org/10.26434/chemrxiv.12673436.v1

25. Dykman, L.A.: Gold nanoparticles for preparation of antibodies and vaccines against infectious diseases. Expert Rev. Vaccines (2020). https://doi.org/10.1080/14760584.2020.1758070

26. Chen, H.W., Huang, C.Y., Lin, S.Y., Fang, Z.S., Hsu, C.H., Lin, J.C., Chen, Y.I., Yao, B.Y., Hu, C.M.J.: Synthetic virus-like particles prepared via protein corona formation enable effective vaccination in an avian model of coronavirus infection. Biomaterials 106, 111-118 (2016)

27. Staroverov, S.A., Volkov, A.A., Mezhenny, P.V., Domnitsky, I.Y., Fomin, A.S., Kozlov, S.V., Dykman, L.A., Gully, O.I.: Prospects for the use of spherical gold nanoparticles in immunization. Appl. Microbiol. Biotechnol. 103(1), 437-447 (2019)

28. Staroverov, S.A., Vidyasheva, I.V., Gabalov, K.P., Vasilenko, O.A., Laskavyi, V.N., Dykman, L.A.: Immunostimulatory effect of gold nanoparticles conjugated with transmissible gastroenteritis virus. Bull. Exp. Biol. Med. 151(4), 436-439 (2011)

29. Sekimukai, H., Iwata-Yoshikawa, N., Fukushi, S., Tani, H., Kataoka, M., Suzuki, T., Hasegawa, H., Niikura, K., Arai, K., Nagata, N.: Gold nanoparticle-adjuvanted S protein induces a strong antigen-specific IgG response against severe acute respiratory syndrome-related coronavirus infection, but fails to induce protective antibodies and limit eosinophilic infiltration in lungs. Microbiol. Immunol. 64(1), 33-51 (2020)

30. Sarkar, P.K., Chaudhary, A.K.: Ayurvedic Bhasma: the most ancient application of nanomedicine. J. Sci. Ind. Res. 69, 901-905 (2010)

31. Prajapati, P.K., Sarkar, P.K., Nayak, S.V., Joshi, R.D., Ravishankar, B.: Safety and toxicity profile of some metallic preparations of Ayurveda. Anc. Sci. Life. 25(3), 57-66 (2006) 
32. Beaudet, D., Badiles, S., Kuruvinashetti, K., Kashani, A.S., Jaunky, D., Ouellette, S., Piekny, A., Packirisamy, M.: Comparative study on cellular entry of incinerated ancient gold particles (Swarna Bhasma) and chemically synthesized gold particles. Sci. Rep. 7, 1-12 (2017)

33. Sharma, R., Bhatt, A., Thakur, M.: Physicochemical characterization and antibacterial activity of Rajata Bhasma and silver nanoparticle. AYU. 37, 71-75 (2016)

34. Singh, R.K., Kumar, S., Aman, A.K., Karim, S.M., Kumar, S., Kar, M.: Study on physical properties of Ayurvedic nanocrystalline Tamra Bhasma by employing modern scientific tools. J. Ayurveda Integr. Med. 10(2), 1-6 (2017)

35. Singh, T.R., Gupta, L.N., Kumar, N.: Standard manufacturing procedure of Teekshna Lauha Bhasma. J. Ayurveda Integr. Med. 7, 100-108 (2016)

36. Nagarajan, S., Krishnaswamy, S., Pemiah, B., Rajan, S., Krishnan, U., Sethuraman, S.: Scientific insights in the preparation and characterisation of a lead-based Naga Bhasma. Indian J. Pharm. Sci. 76(1), 38-45 (2014)

37. Kale, B., Rajurkar, N.: Synthesis and characterization of Vanga Bhasma. J. Ayurveda Integr. Med. 10(2), 1-9 (2017)

38. Chavare, A., Chowdari, P., Ghosh, S., Pawar, P., Patkar, M., Dakave, S., Gota, V., Chaudhari, P., Chiplunkar, S.V., Kane, S., Suresh, A.K., Bellare, J.: Safety and bioactivity studies of Jasad Bhasma and its in-process intermediate in Swiss mice. J. Ethnopharmacol. 197, 73-86 (2017)

39. Kar, S., Gurubasavaraja, B., Vikaram, S., Sriharsha, K.V., Deshpande, R.: Ayurvedic preventive and curative protocol for Covid 19 - a proposal. J. Ayurveda Integr. Med. Sci. 5(2), 92-108 (2020)
40. Bajaj, S., Ahmad, I., Raisuddin, S., Vohora, S.B.: Augmentation of non-specific immunity in mice by gold preparations used in traditional systems of medicine. Indian J. Med. Res. 113, 192-196 (2001)

41. Khedekar, S., Priya, A., Patgiri, B., Nariya, M., Prajapati, P.K.: Immunomodulatory activity of Swarna Prashana in Charle's Foster albino rats. J. Ayu. Med. Sci. 1(2), 90-96 (2016)

42. Bafna, P.S., Patil, S.D.: Physicochemical characterisation and antiinflammatory activity of Ayurvedic herbo-metallic Tamra Bhasma in acute and chronic models of inflammation. Mater. Technol. 33(10), 681-688 (2018)

43. Soni, H., Sharma, S., Malik, J.K.: Synergistic prophylaxis on COVID-19 by nature golden heart (Piper betle) \& Swarna Bhasma. Asian J. Res. Dermatol. Sci. 3(2), 21-27 (2020)

44. Gauri, A., Yadav, P., Prajapati, P.K.: Possible potential of Tamra Bhasma (calcined copper) in COVID-19 management. J. Res. Ayurvedic Sci. 4(3), 113-120 (2020)

45. World Health Organization. Clinical management of COVID-19. 2020. https://www.who.int/publications/i/item/clinicalmanagem ent-of-covid-19.

Publisher's Note Springer Nature remains neutral with regard to jurisdictional claims in published maps and institutional affiliations. 